EREM 77/3

Journal of Environmental Research, Engineering and Management Vol. 77 / No. 3 / 2021 pp. 86-98

DOI 10.5755/j01.erem.77.3.25317
Understanding Drivers of Renewable Energy Firm's Performance

Received 2020/02

Accepted after revision 2021/07

\title{
Evaluation of Microalgae's Plastic Biodeterioration Property by a Consortium of Chlorella sp. and Cyanobacteria sp.
}

\author{
Natanamurugaraj Govindan*, Prakash Bhuyar, Ho Xuan Feng, \\ Mohd Hasbi Ab. Rahim, Gaanty Pragas Maniam \\ Algae Biotechnology Laboratory, Faculty of Industrial Sciences and Technology, Universiti Malaysia Pahang, \\ Lebuhraya Tun Razak, 26300 Gambang, Kuantan, Pahang, Malaysia
}

\section{Sathyavathi Sundararaju}

Department of Pathology, Sidra Medicine, Doha -26999, Qatar

\section{Sudhakar Muniyasamy}

Nanostructured and Advanced Materials, Chemicals Cluster, Council for Scientific and Industrial Research (CSIR),

Pretoria, South Africa

\section{*Corresponding author: natanam@ump.edu.my}

Malaysia is one of the top eight countries that has a drawback of mismanaged plastic waste. This study intended to investigate polymer degradation using the biological technique with the help of microalgae to minimise the time required for biodegradation. This research article aims to identify the collected sample with the most suitable microalgae for the biodegradation of microplastic and to analyse the biodegradation of the polymer by microalgae. The results revealed that the consortium of Chlorella sp. and Cyanobacteria sp. were able to deteriorate low-density polyethene (LDPE sample) through several stages, and this was confirmed by UV-Spec, FESEM, EDX, CHNO, FTIR and DSC analysis. The results obtained revealed that microalgae producing exopolysaccharides (EPS) decreased the carbon and oxygen ratio. According to SEM micrographs, microalga may colonise, agglomerate, and adhere 
microplastics to its surface, regardless of its fractional size. The EDX analysis showed that the initial composition of carbon was $92.30 \pm 1.23 \%$, while after the incubation, the carbon composition started decreasing from $53.18 \%$ to $39.12 \pm 1.08 \%$. Finally, there was a $37.91 \%$ decrease in carbon weight from elemental analysis.

Keywords: phycodegradation, microalgae, plastic pollution microplastics, EPS.

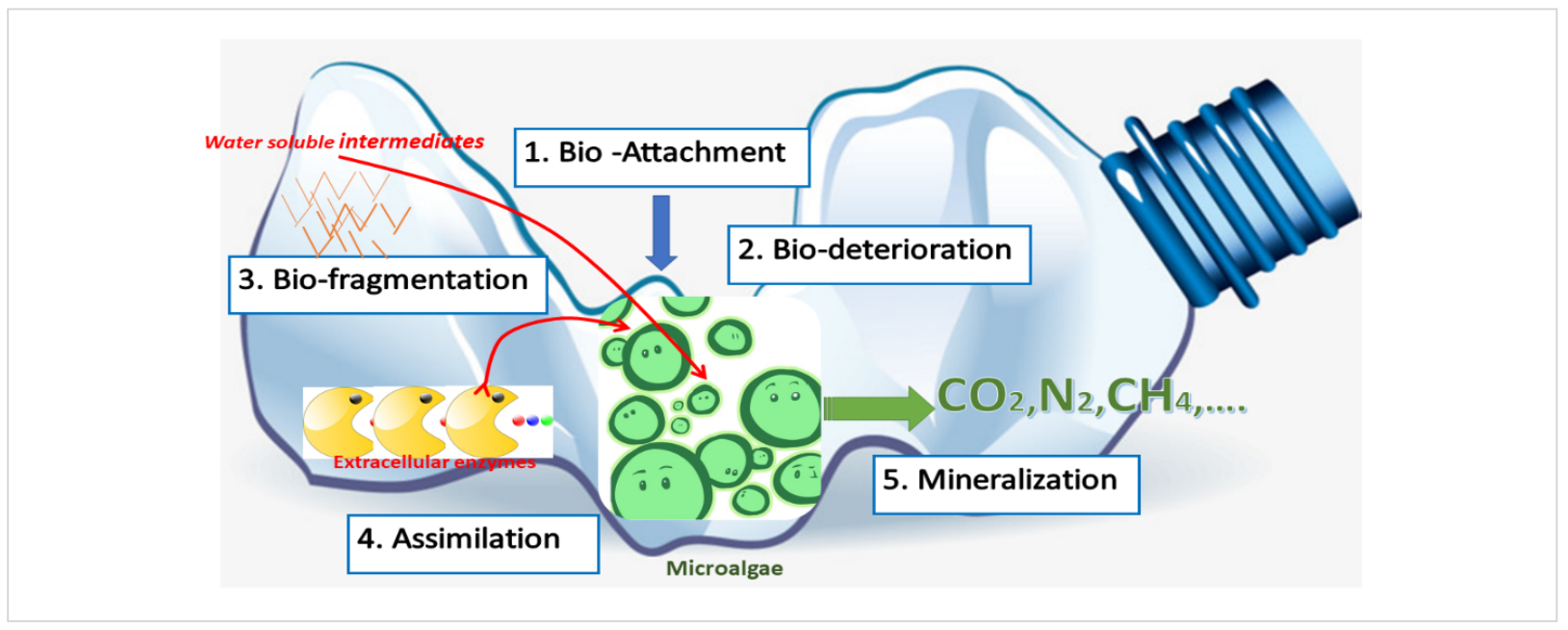

Graphical Abstract

\section{Introduction}

The amount of plastic trash that flows into the oceans every year is widely increasing. If current rates of plastic manufacturing and garbage accumulation continue, the yearly amount of unmanaged garbage is expected to more than quadruple by 2050 , and the cumulative amount of ocean plastic might increase by order of magnitude by 2025 compared with 2010 levels (Cole et al., 2011; Lau et al., 2020). Due to its exceptional properties such as lightweight, durability, and low cost, plastic has been widely utilized as a packaging material for plastic bags, plastic trays, plastic bottles and cups (Rensburg et al., 2020). Also, the chemical constituent of polyethylene is highly stable due to the solid intermolecular bonding. Its degradation has become a significant problem nowadays, while 25 million tons of plastic waste accumulate every year (Govindan et al., 2019).

Although there are many types of plastics like polypropylene (PP), polyvinyl chloride (PVC), polyethylene terephthalate (PET), low-density polyethylene (LDPE) and high-density PE (HDPE), only a few among them are mainly used for commercial purposes (Ojha et al., 2017;
Park et al., 2019). There are three traditional methods commonly used to treat polyethylene waste (recycling, landfill, and incineration) (Mostafa et al., 2018). Several studies indicate that polyethylene could be degraded by photo-degradation and chemical degradation methods (Genovese et al., 2016; Peixoto et al., 2017) In addition, biodegradation of polyethylene occurs by two mechanisms: hydro-biodegradation and oxo-biodegradation (Singh and Sharma, 2008). Microorganisms can easily attach to the surface of hydrophilic polyethylene, with the matrix being hydro-biodegraded (Lv et al., 2019). The usage of enzymes and microbes for the bioremediation of plastics can still break down the larger polymeric molecules into simple forms (Saengsawang et al., 2020).

Biodegradation of polyethylene mainly using microbial consortium is considered an environmentally friendly method. The main limitation of conventional petroleum-based plastics is the fact that plastics get fragmented under abiotic factors (UV radiation, temperature, physical stress) for a long time, and they cannot be decomposed entirely and assimilated by microorganisms 
(biotic factors) in a biodegradation process (Kunlere et al., 2019). This alarming scenario triggers attention towards the design of new enzyme structures capable of degrading synthetic polymers effectively and in a short period (Paço et al., 2017).

Some microalgae species, such as blue-green algae, diatoms, and green algae, can also break down polyethylene (Kumar et al., 2017). Microalgae are green photosynthetic organisms that prefer to adhere to polymers. Furthermore, the most common bacteria identified in wastewater ecosystems are blue-green microalgae. Due to the availability of nutrients, water, and sunlight, microalgal colonies have been found to be dominating on the surface of the discarded polyethylene bags (Cunha et al., 2019). As a result of the available literature, it has been established that microalgae can colonise the surface of polyethylene sheets and that biodegradation occurs under normal conditions (Cunha et al., 2019; Lv et al., 2019). A microalgae consortium was used for a recent study showing some positive hetero aggregation on the polymers. Phycodegradation is considered a better method to treat plastic waste due to its relevance and eco-friendly nature compared with other techniques (Gnanavel et al., 2012). The main objective of the present study stands to degrade the plastics in an environmentally friendly manner by using photosynthetic microalgae. The steps involve collecting the samples, identifying microalgae, collecting plastic polymers, screening, polymer treatment, and analysis of degradation results.

\section{Materials and Methods}

\section{Collection of samples}

Three distinct locations yielded a total of ten waste polyethylene bags with a green mat of photosynthetic microalgae, such as Teluk Chempedak (5 samples), Taman Gelora (3 samples) and Pekan coast (2 samples), around Kuantan city (3.812601-103.372003.3'48'45.36"N, $\left.103^{\circ} 22^{\prime} 19.21^{\prime \prime E}\right)$, Pahang, Malaysia. Sampling was done in January, 2019. Water samples were obtained using sterile vials in addition to the HDPE samples. These are the areas where a large number of industries have been built with a considerable amount of human economic activity. Within 24 hours, the collected polyethylene bags were transported to the laboratory, labelled with their locations, and stored.

\section{Collection, isolation, and identification of microalgae}

The microalgal samples from both the polyethylene bags and the water samples were serially diluted with sterile distilled water. Based on the spread plate approach, all serials from 10-1 to 10-10 were employed as inoculums $(1 \mathrm{~mL})$ in various solidified media, including BBM (for green microalgae) and BG-11 (for bluegreen algae). The inoculated Petri dishes were incubated at room temperature $\left(25 \pm 2{ }^{\circ} \mathrm{C}\right)$ for a week under 12 hours of light. The microalgae formed as colonies on the surface of the solidified media were tagged and photographed using an Olympus $\mathrm{CH} 2 \mathrm{O}$ i fluorescence microscope. Pure microalgal cultures were isolated using a variety of streak plate methods and solidified media. Based on the manual 'Microalgae Identification for Aquaculture', all of the various microalgae were morphologically recognised (Karlo et al., 2015; Bhuyar et al., 2020).

\section{Mass cultivation of microalgae}

The cultures ( $20 \mathrm{~mL}$ of media with microalgae) were shaken using the shaker for two weeks under the proper light condition to produce inoculum. After two weeks, about $50 \mathrm{~mL}$ of the inoculum was transferred again into another 2L BG-11 media in $5 \mathrm{~L}$ conical flasks to obtain a pure mass subculture of microalgae. The subcultures were shaken for another two weeks again under proper light conditions. The subcultures were observed daily for growth absorbance at $680 \mathrm{~nm}$ for approximately two weeks (Govindan et al., 2019).

\section{Determination of growth of microalgae}

The growth of microalgae was determined using the cell turbidity method. Cell turbidity was determined by measuring the optical density at $680 \mathrm{~nm}$ (OD680) using a UV-Vis spectrophotometer (Spectroquant Pharo 300 Merck, Singapore) (Sue et al., 2011; Khammee et al., 2020) in regular time intervals, and absorption was measured. The turbidity was measured and recorded daily for two weeks. 


\section{Biological treatment of polyethylene}

For the biological treatment, low density (LD) polyethylene sheets were chosen and trimmed to $1 \mathrm{sq}$. $\mathrm{cm}$. The bacterial contamination of the polyethylene sheets was overcome by UV pre-treated before being used in the algae treatment. The LD polyethylene sheets were used to treat biologically and individually with the microalgae culture media (BG-11) utilising the selected microalgae based on their dominance over other microalgae, which are a consortium of both Chlorella Sp. (green microalga) and Cyanobacteria sp. (blue-green alga). In $500 \mathrm{~mL}$ Erlenmeyer flasks, $200 \mathrm{~mL}$ culture media were created, with two conical flasks for each culture media named control and LD, respectively. All culture media were autoclaved at $121^{\circ} \mathrm{C}, 15 \mathrm{psi}$ for 15 minutes before incubation except for the control.

\section{FESEM analysis and EDX measurement}

FESEM (JEOL JSM 7800F, Japan) optimal voltage at 10 $\mathrm{kV}$ was used to analyse the microalgae-treated polythene sheets qualitatively. A sample tipped in a micro tip was transferred to a sample plate and analysed by several imaging modes. EDX analysis was conducted with the same FESEM EDX (OXFORD, UK) instrument, which is confirmed for the elemental composition of algae treated and control samples. The materials were ionised for 20 minutes using an ion sputter on a metal stub. After platinum coating, the samples were held under vacuum for microscopy and photography at magnifications ranging from 50 to 15000 .

\section{Fourier transform infrared spectroscopy (FTIR) analysis}

A Perkin Elmer Spectrum 100 FTIR spectrometer, USA, was used to obtain spectra from the treated polymer. FTIR spectroscopy can be used as physiological fingerprints to study the structure and chemical bonding of the algal biomass, and especially to identify the functional groups. The instrument was equipped with a mercury cadmium telluride (MCT) detector, and the spectra were recorded in the frequency range of 450 to $4000 \mathrm{~cm}^{-1}$ at a resolution of $4 \mathrm{~cm}^{-1}$. For FTIR measurement, the polymer samples were used directly to carry out the scanning (Bhuyar et al., 2020).

\section{$\mathrm{C}, \mathrm{H}, \mathrm{N}$ and $\mathrm{O}$ analysis}

The microalgae treated LDPE film together with the control was taken out and allowed to dry overnight. The samples were ground into a powder form and weighed before sending to the analyser. Qualitative elemental analysis of crude algal biomass was determined and analysed by a CHNO elemental analyser (ELTRA GmbH. Retsch-Allee 1-5 42781 Haan, Germany). The higher heating value (HHV) of biomass-based $\mathrm{CHN}$ was calculated using the Dulong formula (Sudhakar and Premalatha, 2015).

\section{Differential scanning calorimetry (DSC)}

The differential scanning calorimetry (DSC) was conducted with a Mettler Toledo 821 equipment (Mettler Toledo, Schwerzenbach, Switzerland) using control and treated LDPE samples of 4-6 mg. The heating and cooling programs were performed at a $10^{\circ} \mathrm{C} / \mathrm{min}$ speed in a nitrogen atmosphere $(60 \mathrm{~mL} / \mathrm{min})$. The DSC program was carried out in three stages: the first heating took place from $30^{\circ} \mathrm{C}$ to $200{ }^{\circ} \mathrm{C}$, followed by a cooling process up to $30^{\circ} \mathrm{C}$ to $-20^{\circ} \mathrm{C}$ followed by a second heating up to $250^{\circ} \mathrm{C}$. The first heating was carried out to remove the thermal history of the materials. The melting temperature, $T_{m}$, and the melting enthalpy, $\Delta H_{m}$, were obtained from the second heating.

\section{Results and Discussion}

\section{Identification and species description}

At the primary screening, the microalgae species were mixed by different species. The microalgae sample was grown on the BG-11 Agar medium by spreading and streaking techniques (Fig. 1). A single drop of microalgae culture was placed on the glass slide and slowly covered with a coverslip, and was observed under the microscope. The identification of the microalgae was made by using fluorescence microscope analysis (Olympus, BX53). Two dominating species of microalgae were identified from all the sampling locations. The two different groups of microalgae, including green algae and blue-green algae, were isolated and identified. Among the green microalgae isolated from the 
Fig. 1. The microalgae primary screening by BG-11 Agar Medium: (a) the mixture of microalgae isolation by the streak plate technique; (b) the mixture of microalgae isolation by the spread plate technique
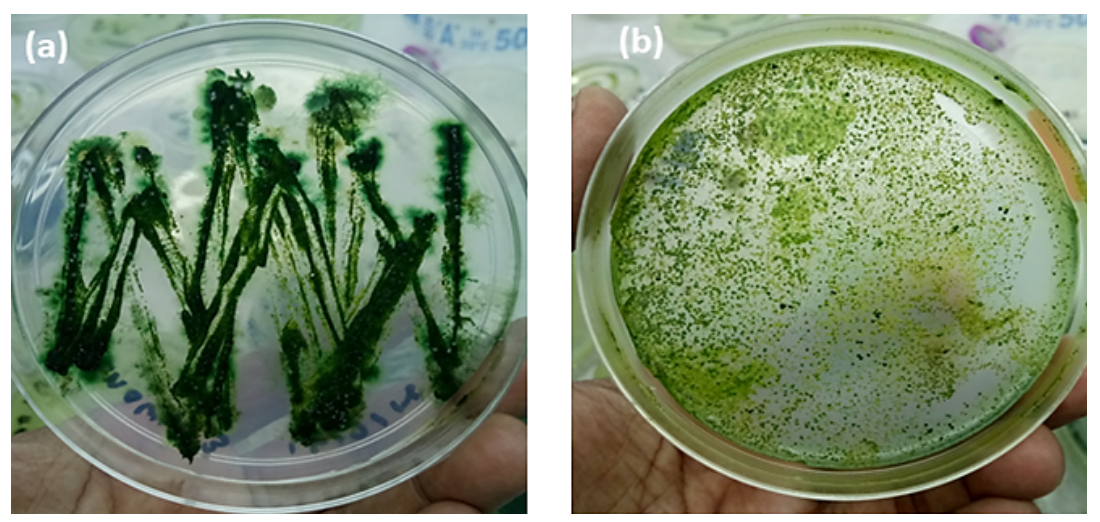

Fig. 2. The fluorescent microscopy for mmicroalgae species identification: (a) Chlorella sp. with round-shaped cells; (b) Cyanobacteria sp. found in the chains

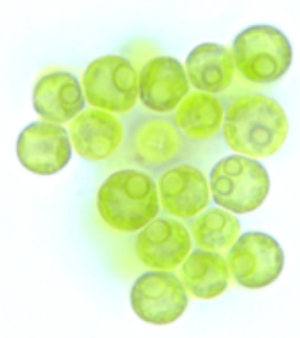

$a$

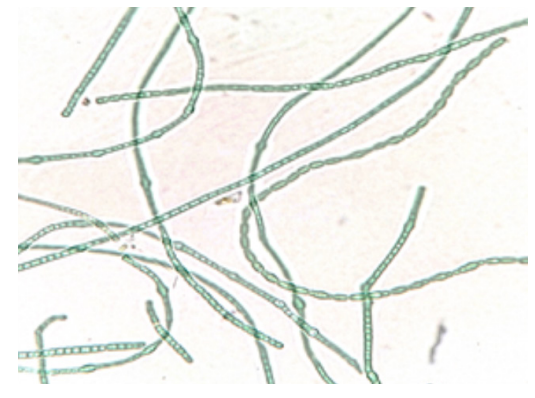

$b$ collected polythene bags and seashore water, Chlorella sp. (Fig. 2 a) was found to be the dominant species. Similarly, Cyanobacteria sp. (Fig. 2b) blatantly dominated the blue-green algae compared with all three sites.

\section{Growth analysis of microalgae}

Spectrophotometry is a rapid and convenient indirect method to take the optical density (OD) reading at a specific wavelength. $\mathrm{OD}$ is represented in terms of transmittance applied by the Beer-Lambert Law of Absorbance (Adrien, 1998). Fig. 3 shows the graph that has been interpreted from the absorbance of the microalgae culture in the BG11 media at $680 \mathrm{~nm}$ using Thermo-Scientific Genesys $10 \mathrm{~S}$ UV/VIS Spectrophotometer from $0 \mathrm{hr}$ to $24 \mathrm{hr}$ and day 1 to day 30. The consortium of Cyanobacteria sp. and Chlorella sp. microalgae showed maximum growth compared with the single sp. growth of Cyanobacteria sp. and Chlorella sp. Fig. 3 indicates that the consortium growth was higher compared with separate single algae growth. The results showed that in the consortium of both species they were helping each other for growth enhancement. The results were compared with other research carried out elsewhere (Aslam et al., 2018; Padmaperuma et al., 2018).

The microalgae consortium was harvested when they reached the exponential phase because, during this phase, the growth of microalgae is maximum and rapid as all the nutrients in the growth medium were consumed by the microalgae for their rapid multiplication. 
Fig. 3. The growth rate of microalgae observed by UV absorbance at $680 \mathrm{~nm}$

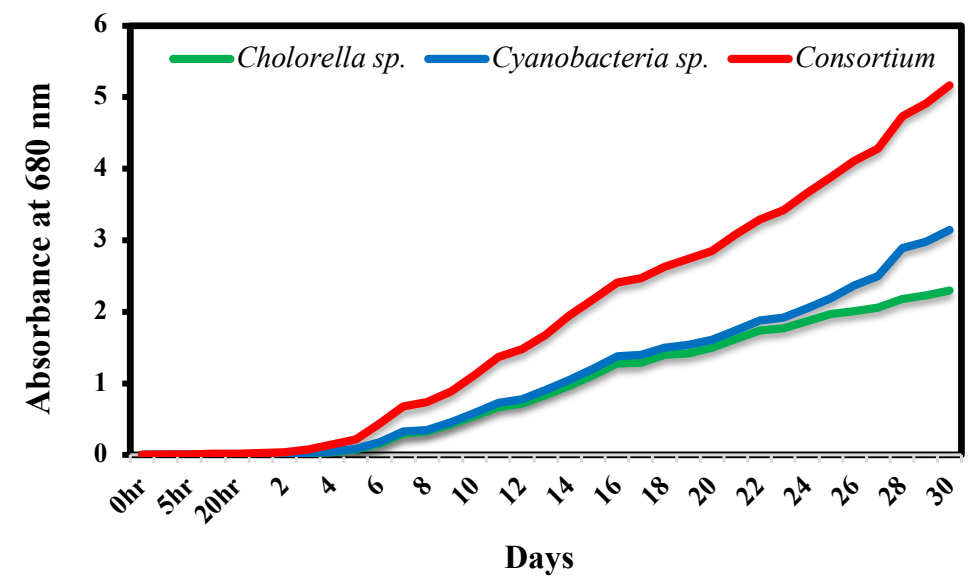

According to studies, exponential growth gives the maximum population of the microalgae than the stationary phase because, during the stationary phase, cell division of the microalgae becomes slow due to the lack of nutrients necessary for their growth (Price and Farag, 2013; Maity et al., 2014).

The microalgae sample was harvested on day 30 , and the sample was placed in the new $2 \mathrm{~L}$ of BG-11 media in a $5 \mathrm{~L}$ conical flask to ensure that the microalgae could grow and propagate at the highest rate with a sufficient amount of nutrients in the fresh medium. Due to the rapid growth, the consortium was selected for further research in the biodegradation of polymers. Next, the microalgae sample continued their other cultivation process with the addition of the polymer (LDPE).

Fig. 3 shows the microalgae growth under regulated circumstances. Chlorella sp. was found to be in a stationary phase without renewal after 30 days of growth, while Cyanobacteria sp. and the consortium were still in an exponential phase. The initial dilution done by the consortium secured the exponential phase towards the end of the trial period. The cell abundance of each microalga at low concentrations of polyethylene was assessed at the end of the experiment and compared with the control groups (Table 1). In the microplastics condition cultures, both blue-green microalgae species showed a decrease

Table 1. The cell abundance (cells $\mathrm{mL}^{-1}$ ) for each microalga studied at the end of the experimental period. Cell abundance variation was calculated for the microplastic conditions against the control for each microalga

\begin{tabular}{c|c|c|c}
\hline \multirow{2}{*}{ Microalgae } & $\begin{array}{c}\text { Microplastic } \\
\text { concentration }\end{array}$ & $\begin{array}{c}\text { Cell abundance } \\
\left(10^{4} \text { cells/mL-1 }\right)\end{array}$ & $\begin{array}{c}\text { Cell abundance } \\
\text { variation }(\%)\end{array}$ \\
\hline \multirow{2}{*}{ Consortium } & Control & $6897 \pm 112$ & - \\
\cline { 2 - 4 } & LDPE & $4763 \pm 167$ & -28 \\
\hline \multirow{2}{*}{ Cyanobacteria sp. } & Control & $1598 \pm 68$ & - \\
\cline { 2 - 4 } & LDPE & $1346 \pm 143$ & -23 \\
\hline \multirow{2}{*}{ Chlorella sp. } & Control & $496 \pm 54$ & - \\
\hline
\end{tabular}


in cell abundance compared with the control groups (Table 1). A substantial drop ( $p>0.05)$ in LDPE microplastic concentrations was reported in the consortium, with a more pronounced decrease (28\%) in the low microplastics (LDPE) concentration. Though the decrease in cell abundance was higher for the high microplastics concentration condition (23 \%) in Cyanobacteria sp. cultures, no significant differences were identified between microplastic concentration treatments in Cyanobacteria sp. cultures. The cell abundance of the microalgae Chlorella sp. did not differ significantly between the microplastic exposure settings and the control treatment ( $p>0.05)$.

However, the growth rate of cyanobacteria is usually much lower than that of many algal species compared with previous studies (Skulberg and Utkilen, 1999). Slow growth rates require long water retention times to enable a bloom of cyanobacteria to form. Therefore, cyanobacteria do not bloom in water with short retention times. The consortium of both species helps each other for the rapid growth improvement and shows an increase in cell abundance.

\section{FESEM-EDX measurement}

The reduced size of the consortium's exopolysaccharides (EPS) was confirmed by SEM images (Fig. 4). These micrographs also demonstrated that the consortium's exopolymer size and type did not allow for proper aggregation of microplastics larger than 20 $\mathrm{mm}$, but they did reveal its microplastics colonisation capability. The SEM pictures of Cyanobacteria sp. (Fig. $4 \mathrm{a}, \mathrm{b})$ revealed that the EPS tended to form a network, which benefits the capitation, aggregation, and adhesion of Cyanobacteria sp. and Chlorella sp. microplastics consortium. The microalga and EPS agglomerates

Fig. 4. FESEM showing degradation by forming groves: (a) the microalgae consortium started colonising on the LDPE; (b) the consortium releasing EPS followed by groove formation; (c) microalgae started colonising on the polyethylene; (d) LDPE and consortium interaction
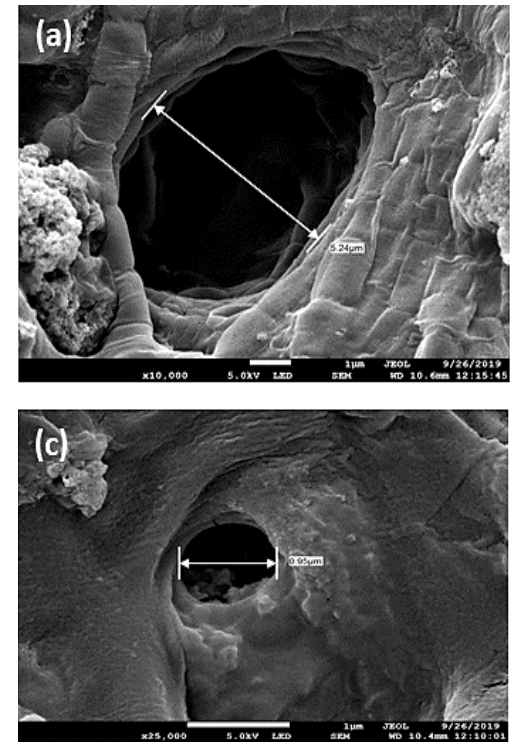

(homo-aggregates) were visible in SEM images (Fig. 4 c, d), with EPS forming a viscous mesh. Cyanobacteria sp. colonises and coats the microplastics, as shown by fluorescence microscopy, with no microplastics visible aggregated on the surface. The SEM scans of the consortium's EPS revealed a fibrous, thick, and vicious
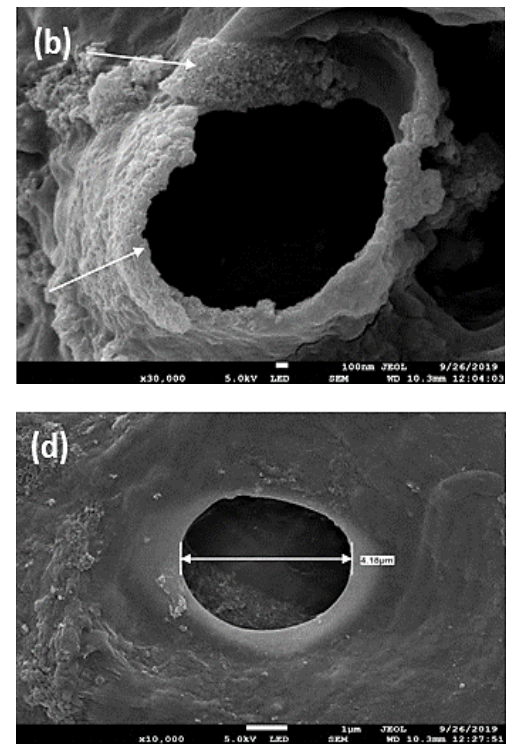

character. The SEM micrographs also revealed that this microalga could colonise, agglomerate, and adhere microplastics to its surface regardless of the fraction size. Fig. 4 shows the colonisation potential of the consortium and its ability to create hetero aggregates with the help of microplastics. 
Energy dispersive analysis was conducted to study the elemental analysis. The results were analysed from Fig. 5. At the early stage of incubation, the LDPE control sample with microalgae showed the carbon composition as $92.30 \pm 1.23 \%$, and during the incubation process, the carbon composition decreased to 53.18 $\%$ and turned out to be $39.12 \pm 1.08 \%$. The oxygen composition throughout the incubation time increased by about $42.63 \pm 0.94 \%$ (which is from $7.70 \pm 0.54 \%$ to $12.63 \pm 0.34 \%$ ) during the biodegradation process.

Fig. 5. Energy dispersive $x$-ray analysis of LDPE after microalgae treatment under $5 \mathrm{kv}$ at $2000 \mathrm{X}$

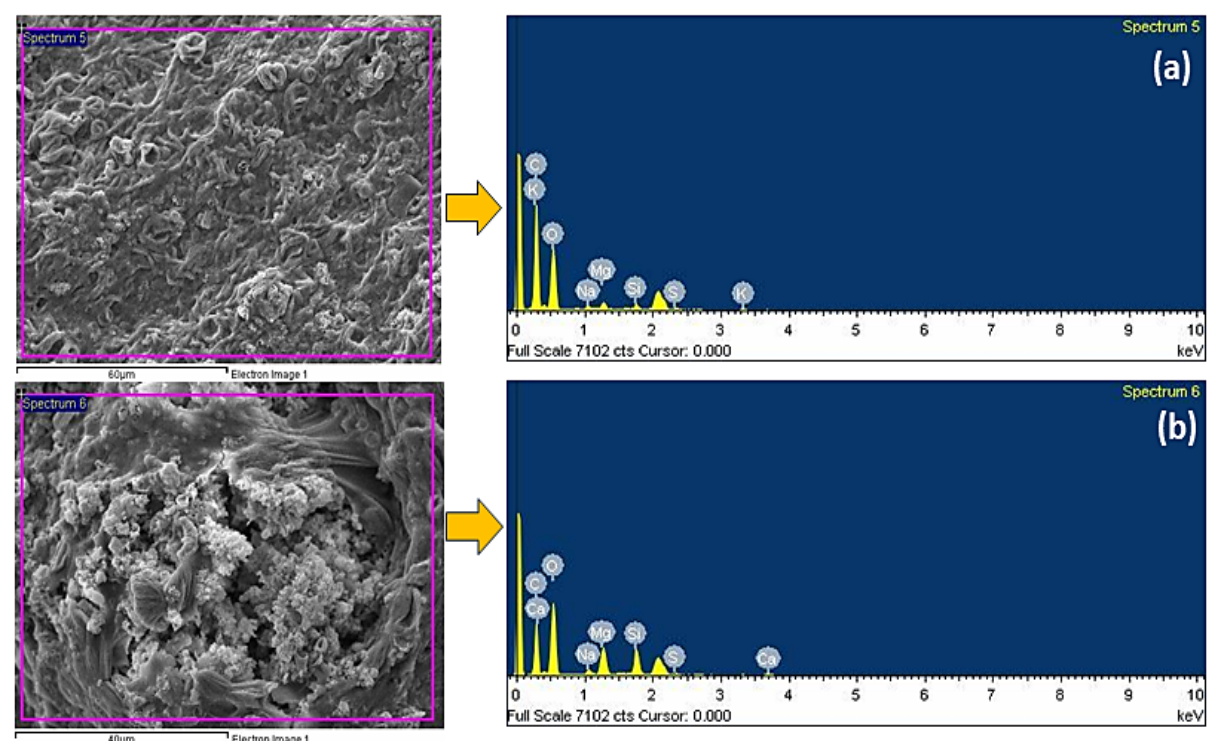

The catabolic reaction occurred on the LDPE fragments where the carbon atoms were degraded by the microalgae when oxygen gases were released. EDX analysis showed few different elements from the control sample, as shown in Fig. 5. These different elements appeared due to the production of extracellular enzymes by microalgae for the accumulation and possible degradation of polymers. The treated samples showed the occurrence of sodium, magnesium, silicate, sulphur, and calcium. The previous research has reported that microalgae release some enzymes such as exopolysaccharides when they encounter polymers and then start accumulating on the polymers' surface (Cunha et al., 2019; Bhuyar et al., 2019)

\section{Fourier transform infrared spectroscopy (FTIR) analysis}

According to the existing literature, biodegradable elements can be easily discovered in recycled polypropylene using the FTIR approach. Some biodegradable polymers' characteristic bands (PLA, PHB, and TPS) do not overlap with the PP characteristic bands (Shah et al., 2016). Fourier transform infrared spectroscopy (FT-IR) was widely used to identify the polymer's composition and differentiate the types between polymers. Each polyethene type may be different due to branching in their chain based on the number of atoms and size of the chain (Jung et al., 2018a). FTIR has its own advantages in that it requires less sample preparation and can investigate the entire sample (Park et al., 2019). Generally, FTIR is a non-destructive, simple and efficient method to evaluate the plastic polymer based on infrared absorption representing specific chemical functionality present in the polymer (Guénaëlle et al., 2001).

Fig. 6 shows the FTIR spectrometry analysis of the LDPE microalgae sample acquired before and after the cultivation (or treatment). In this spectrum, one peak is relatively near to the most vigorous intensity with stable $-\mathrm{CH}_{2}$ 
Fig. 6. FTIR spectrum of LDPE at day 30,60 and 90 of cultivation treatment with microalgae

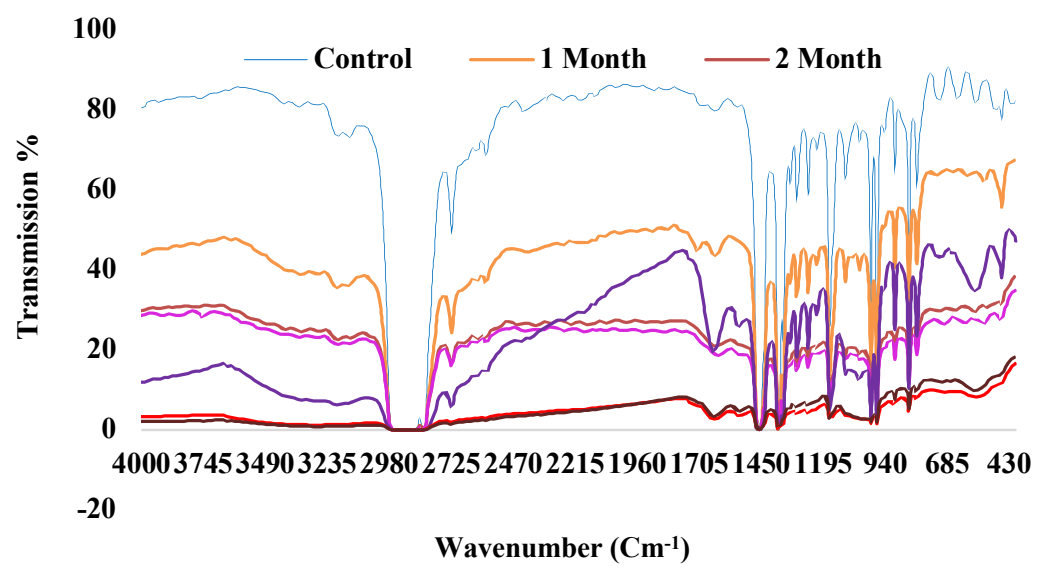

bonding. The peak sited at $2839 \mathrm{~cm}^{-1}$ with $\% \mathrm{~T}$ is 0.007115 . The peak at $2839 \mathrm{~cm}^{-1}$ represents the carbonyl bond which indicates degradation of the polymer. Percentage T (\% T) indicates the absorption of light in the infrared region of the electromagnetic spectrum. Absorption corresponds precisely to the bonds that are present in the molecule or sample. This chosen peak has the most vital stability at the exact band location of $2839 \mathrm{~cm}^{-1}$ with \% T as 0.002774 . There is a slight decrease in $\mathrm{T}(\% \mathrm{~T})$ as they reduce with 0.004341 at $61 \%$, showing that the LDPE started to degrade whilst at the early stage of the biodegradation phase. In other words, the bond between the carbon and hydrogen atoms starts to weaken and lose its asymmetry stability. Although the FTIR method does not quantify the quantity of the biopolymer in the blends, it is a quick and straightforward way to detect these contaminants in the recycled PP process, and it is easily scalable for the plastic recycling sector (Samper et al., 2018). Theoretically, the absorption band identifies LDPE in the range of $717 \mathrm{~cm}^{-1}$ until $2915 \mathrm{~cm}^{-1}$ (Jung et al., 2018b). At $2915 \mathrm{~cm}^{-1}$ of absorption, it has the band's vigorous intensity as $-\mathrm{CH}_{2}$ at symmetry stretching (Sivan, 2011).

\section{$\mathrm{C}, \mathrm{H}, \mathrm{N}$ and $\mathrm{S}$ analysis of treated polymer}

The carbon and hydrogen weight percentage in $\mathrm{C}, \mathrm{H}, \mathrm{N}$ and $\mathrm{S}$ analysis are the essential parameters in determining the degradation ability of microalgae. During the degradation process, the carbon weight percentage for low-density polyethylene decreased significantly, by $37.91 \%$, as shown in Fig. 7.

Fig. 7. Comparative analysis of $\mathrm{C}, \mathrm{H}, \mathrm{N}$ and S elements present in polymer sheet: spectrum analysis of elements in control and treated low-density polyethylene (LDPE)

Carbon


As microalgae used polyethylene as a carbon source for growth, random chain links and cross-linking transpired, leading to a decrease in the carbon backbone. The material becomes brittle and subject to fragmentation (Cai et al., 2018). Furthermore, the hydrogen content of LDPE decreased as the cleavage of hydrogen and oxidation during the degradation process. Furthermore, sulphur and nitrogen are detected according to the material characterisation and the quality control testing of polymers and plastics. Sulphur-containing compounds are often added as plasticisers, flame retardants, and heat stabilisers (Luckachan and Pillai, 2011).

In comparison, nitrogen-containing compounds are used in polymers and plastics to trigger a polymerisation reaction. They can also be used as additives for the addition of specific properties to polymers and plastics. As additives, nitrogen-containing compounds provide the final product with specific properties, and they act as stabilising emulsion polymers, chain transfer agents and other polymerisation modifiers to control molecular weight, plasticisers to increase flexibility, stabilisers to prevent polymer degradation, crosslinkers used to modify polymer networks (Shahnawaz et al., 2019).

\section{Differential scanning calorimetry of polyethylene}

The oxidative deterioration of polyethylene (PE) composites is studied using differential scanning calorimetry equipment. In a typical test, a sample is heated to $500^{\circ} \mathrm{C}$ in a nitrogen environment. The commencement of exothermic oxidation is timed and recorded. Alternatively, the polymer samples can be heated in oxygen, and the temperature at which oxidation begins can be determined (Khanam and AlMaadeed, 2015). DSC can be used to determine the glass transition temperature $(\mathrm{Tg})$ of $\mathrm{PE}$ composites, as an endothermic shift from the baseline is observed in the case of crystallisable polymers. The DSC curve for a polymer composite of control and treated LD polyethylene is shown in Fig. 8. This graph shows the crystallisation temperature (Tc) and melting temperature (Tm). DSC measurements for PE composites are typically performed in a nitrogen environment with heating and cooling speeds of $10{ }^{\circ} \mathrm{C} / \mathrm{min}$. The following techniques can be used: (i) heating from $30^{\circ} \mathrm{C}$ to $500{ }^{\circ} \mathrm{C}$, (ii) cooling from $300^{\circ} \mathrm{C}$ to $30^{\circ} \mathrm{C}$, and (iii) heating from $30^{\circ} \mathrm{C}$ to $300^{\circ} \mathrm{C}$.

Fig. 8 shows that the melting temperature, Tm, remains constant, ranging between $143.4^{\circ} \mathrm{C}$ and $155.1^{\circ} \mathrm{C}$. When

Fig. 8. The differential scanning calorimetry curve: (a) LDPE control; (b) LDPE treated with a consortium of microalgae

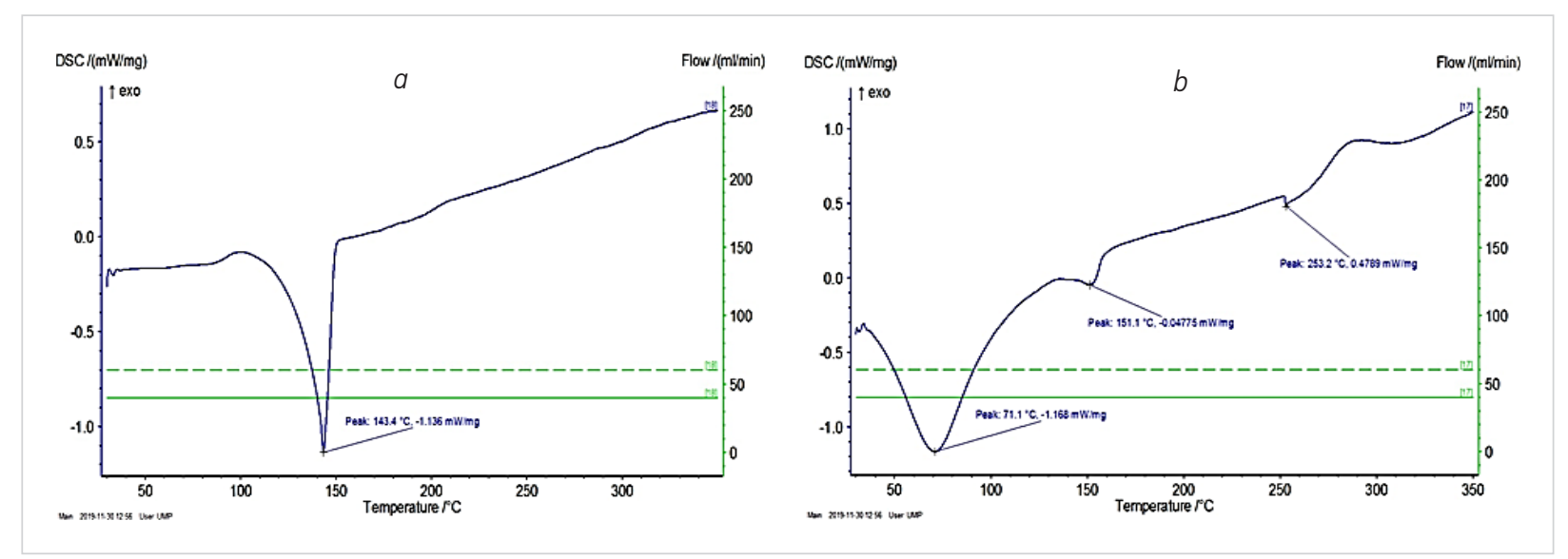

compared with the Tc acquired from the DSC cooling procedure, it can be shown that LDPE crystallises at 124.5 ${ }^{\circ} \mathrm{C}$ and that the crystallisation temperature in all treated samples containing degraded polymers of LDPE reduced falling between $120.5^{\circ} \mathrm{C}$ and $121.6^{\circ} \mathrm{C}$. As the enthalpy values of crystallisation and melting fell, biodegradable polymers in the PE matrix decreased crystallinity. Because biodegradable polymers function as contaminants and hence diminish the free volume of PP, the loss in crystallinity could be attributed to biodegradable polymers in the mix, making the peak of PE chains more complicated (Amin et al., 2019). As a result, the inclusion of biodegradable polymers influences the treated polyethene's mechanical properties and its thermal performance, 
particularly the PP crystallinity, given that the melting temperature is only minimally altered (Olewnik-Kruszkowska et al., 2016; Li et al., 2018).

\section{Conclusions}

In this study, a consortium of blue-green microalgae was successfully isolated, identified, and used for biodegradation of low-density polyethylene. The consortium (the mixture of Cyanobacteria sp. and Chlorella sp.) biodegraded low-density polyethylene without adding any chemicals or capping agents. The consortium behaves as an economically reducing and stabilising agent to degrade polymers of the size $<100 \mathrm{~nm}$. The consortium secretes various exopolysaccharides such as carbohydrates and proteins. They may act as colonising agents and degradative agents for polymers into monomers. Microalgae secrete exoenzymes and polysaccharides at room temperature. It is observed that the consortium of microalgae has been effectively attached on the low-density polyethylene surface with the highest aggregation. Finally, the characterisation of consortium's morphology, physical and chemical properties of treated polyethylene samples are studied by various analytical techniques such as UV-Spec, FESEM, EDX, CHNO, FTIR and DSC,

\section{References}

Adrien, N. G. (1998). Derivation of mean cell residence time formula. Journal of Environmental Engineering, 124(5), 473-474. https://doi.org/10.1061/(ASCE)0733-9372(1998)124:5(473)

Amin, M. R., Chowdhury, M. A., and Kowser, M. A. (2019). Characterisation and performance analysis of composite bioplastics synthesised using titanium dioxide nanoparticles with corn starch. Heliyon, 5(8), e02009. https://doi.org/10.1016/j.heliyon.2019.e02009

Aslam, A., Thomas-Hall, S. R., Manzoor, M., Jabeen, F., Iqbal, M., Uz Zaman, Q., ... and Tahir, M. A. (2018). Mixed microalgae consortia growth under higher concentration of $\mathrm{CO} 2$ from unfiltered coal fired flue gas: fatty acid profiling and biodiesel production. Journal of Photochemistry and Photobiology B: Biology, 179, 126-133. https://doi.org/10.1016/j.jphotobiol.2018.01.003 Bhuyar, P., Rahim, M. H. A., Sundararaju, S., Ramaraj, R., Maniam, G. P., and Govindan, N. (2020). Synthesis of silver nanoparticles using marine macroalgae Padina sp. and its and it is clear from the results that potential aggregation of the consortium passed through bio-deterioration, bio-fragmentation, assimilation, and mineralisation phase. This study demonstrated that the microalgal colonisation or aggregation of the consortium (Cyanobacteria sp. and Chlorella sp.) acts against both low-density and high-density polyethylene, and designing this biodegradation method targets plastic waste pollution and promises a new environmentally friendly process to treat plastic waste generation. As a result of the current investigation, biodegradation was evident, and the microalgae successfully colonised the polythene sheets' surface. As a result, it was determined that the consortium ( $\mathrm{Cy}$ anobacteria sp. and Chlorella sp.), a filamentous form of blue-green algae, effectively destroys the polyethylene sheet among different kinds of microalgae.

\section{Acknowledgements}

The authors gratefully acknowledge Universiti Malaysia Pahang for the financial assistance through the Internal Research Grant No. RDU190337 and Flagship Grant No. RDU182205. Author [Prakash Bhuyar] is thankful to UMP for providing Doctoral Research Scholarship DRS and PGRS190351 as financial support.

antibacterial activity towards pathogenic bacteria. Beni-Suef University Journal of Basic and Applied Sciences, 9(1), 1-15. https://doi.org/10.1186/s43088-019-0031-y

Bhuyar, P., Sundararaju, S., Rahim, M. H. A., Ramaraj, R., Maniam, G. P., and Govindan, N. (2019). Microalgae cultivation using palm oil mill effluent as growth medium for lipid production with the effect of $\mathrm{CO} 2$ supply and light intensity. Biomass Conversion and Biorefinery, 1-9. https://doi.org/10.1007/s13399-019-00548-5

Bhuyar, P., Yusoff, M. M., Rahim, M. H. A., Sundararaju, S., Maniam, G. P., and Govindan, N. (2020). Effect of plant hormones on the production of biomass and lipid extraction for biodiesel production from microalgae Chlorella sp. Journal of Microbiology, Biotechnology and Food Sciences, 10(1), 671-674. https:// doi.org/10.15414/jmbfs.2020.9.4.671-674

Cai, L., Wang, J., Peng, J., Wu, Z., and Tan, X. (2018). Observation of the degradation of three types of plastic pellets exposed to UV irradiation in three different environments. Science of the 
Total Environment, 628, 740-747. https://doi.org/10.1016/j. scitotenv.2018.02.079

Cole, M., Lindeque, P., Halsband, C., and Galloway, T. S. (2011). Microplastics as contaminants in the marine environment: a review. Marine pollution bulletin, 62(12), 2588-2597. https://doi. org/10.1016/j.marpolbul.2011.09.025

Cunha, C., Faria, M., Nogueira, N., Ferreira, A., and Cordeiro, N. (2019). Marine vs freshwater microalgae exopolymers as biosolutions to microplastics pollution. Environmental pollution, 249, 372-380. https://doi.org/10.1016/j.envpol.2019.03.046

Genovese, L., Lotti, N., Gazzano, M., Siracusa, V., Dalla Rosa, M., and Munari, A. (2016). Novel biodegradable aliphatic copolyesters based on poly (butylene succinate) containing thioether-linkages for sustainable food packaging applications. Polymer Degradation and Stability, 132, 191-201. https://doi. org/10.1016/j.polymdegradstab.2016.02.022

Gnanavel, G., Valli, V. P. M. J., and Thirumarimurugan, M. (2012). A review of biodegradation of plastics waste. International journal of pharmaceutical and chemical sciences, 1(3), 670-673.

Gourier, C., Bourmaud, A., Le Duigou, A., and Baley, C. (2017). Influence of PA11 and PP thermoplastic polymers on recycling stability of unidirectional flax fibre reinforced biocomposites. Polymer Degradation and Stability, 136, 1-9. https://doi. org/10.1016/j.polymdegradstab.2016.12.003

Jung, H. W., Yang, M. K., and Su, R. C. (2018). Purification, characterisation, and gene cloning of an Aspergillus fumigatus polyhydroxybutyrate depolymerase used for degradation of polyhydroxybutyrate, polyethylene succinate, and polybutylene succinate. Polymer Degradation and Stability, 154, 186-194. https://doi.org/10.1016/j.polymdegradstab.2018.06.002

Jung, M. R., Horgen, F. D., Orski, S. V., Rodriguez, C. V., Beers, K. L., and Balazs, G. H. (2018). T. 406 T. Jones, TM Work, KC Brignac, SJ Royer, KD Hyrenbach, BA Jensen, and 407 JM Lynch," Validation of ATR FT-IR to identify polymers of plastic marine debris, 408 including those ingested by marine organisms. Marine Pollution Bulletin, 127, 704-716. https://doi.org/10.1016/j. marpolbul.2017.12.061

Karło, A., Wilk, A., Ziembińska-Buczyńska, A., and Surmacz-Górska, J. (2015). Cultivation parameters adjustment for Effective algal biomass production. Rocznik Ochrona Środowiska, 17(cz. 1), 275-288.

Khammee, P., Ramaraj, R., Whangchai, N., Bhuyar, P., and Unpaprom, Y. (2020). The immobilisation of yeast for fermentation of macroalgae Rhizoclonium sp. for efficient conversion into bioethanol. Biomass Conversion and Biorefinery, 1-9. https:// doi.org/10.1007/s13399-020-00786-y

Khanam, P. N., and AlMaadeed, M. A. A. (2015). Processing and characterisation of polyethylene-based composites. Advanced
Manufacturing: Polymer and Composites Science, 1(2), 63-79. https://doi.org/10.1179/2055035915Y.0000000002

Kunlere, I. O., Fagade, O. E., and Nwadike, B. I. (2019). Biodegradation of low density polyethylene (LDPE) by certain indigenous bacteria and fungi. International Journal of Environmental Studies, 76(3), 428-440. https://doi.org/10.1080/00207233.201 9.1579586

Lau, W.W., Shiran, Y., Bailey, R.M., Cook, E., Stuchtey, M.R., Koskella, J., Velis, C.A., Godfrey, L., Boucher, J., Murphy, M.B. and Thompson, R.C. (2020). Evaluating scenarios toward zero plastic pollution. Science, 369(6510), pp.1455-1461. https://doi. org/10.1126/science.aba9475

Li, P., He, F., Yang, Z., Yang, W., and Yao, J. (2018). The degradability and thermal properties of chiral polyamide-imides synthesised from several l-amino acids: Side group effects. Polymer Degradation and Stability, 147, 267-273. https://doi. org/10.1016/j.polymdegradstab.2017.11.021

Luckachan, G. E., and Pillai, C. K. S. (2011). Biodegradable polymers-a review on recent trends and emerging perspectives. Journal of Polymers and the Environment, 19(3), 637-676. https://doi.org/10.1007/s10924-011-0317-1

Lv, J., Zhao, F., Feng, J., Liu, Q., Nan, F., and Xie, S. (2019). Extraction of extracellular polymeric substances (EPS) from a newly isolated self-flocculating microalga Neocystis mucosa SX with different methods. Algal Research, 40, 101479. https:// doi.org/10.1016/j.algal.2019.101479

Maity, J. P., Bundschuh, J., Chen, C. Y., and Bhattacharya, P. (2014). Microalgae for third generation biofuel production, mitigation of greenhouse gas emissions and wastewater treatment: Present and future perspectives-A mini review. Energy, 78, 104-113. https://doi.org/10.1016/j.energy.2014.04.003

Mostafa, N. A., Farag, A. A., Abo-dief, H. M., and Tayeb, A. M. (2018). Production of biodegradable plastic from agricultural wastes. Arabian journal of chemistry, 11(4), 546-553. https:// doi.org/10.1016/j.arabjc.2015.04.008

Mur, L. R., Skulberg, O. M., and Utkilen, H. (1999). Chapter 2, Cyanobacteria. The environment in toxic cyanobacteria in water: $\mathrm{A}$ guide to their public health consequences, Monitoring and management by Chorus I and Bartram J (Eds) Switzerland, WHO.

Ojha, N., Pradhan, N., Singh, S., Barla, A., Shrivastava, A., Khatua, P., ... and Bose, S. (2017). Evaluation of HDPE and LDPE degradation by fungus, implemented by statistical optimisation. Scientific Reports, 7(1), 1-13. https://doi.org/10.1038/srep39515

Paço, A., Duarte, K., da Costa, J. P., Santos, P. S., Pereira, R., Pereira, M. E., ... and Rocha-Santos, T. A. (2017). Biodegradation of polyethylene microplastics by the marine fungus Zalerion maritimum. Science of the Total Environment, 586, 10-15. https://doi.org/10.1016/j.scitotenv.2017.02.017 
Padmaperuma, G., Kapoore, R. V., Gilmour, D. J., and Vaidyanathan, S. (2018). Microbial consortia: a critical look at microalgae co-cultures for enhanced biomanufacturing. Critical reviews in biotechnology, 38(5), 690-703. https://doi.org/10.1080/073885 51.2017 .1390728

Park, S. A., Jeon, H., Kim, H., Shin, S. H., Choy, S., Hwang, D. S., ... and Oh, D. X. (2019). Sustainable and recyclable super engineering thermoplastic from biorenewable monomer. Nature communications, 10(1), 1-11. https://doi.org/10.1038/s41467019-10582-6

Peixoto, J., Silva, L. P., and Krüger, R. H. (2017). Brazilian Cerrado soil reveals an untapped microbial potential for unpretreated polyethylene biodegradation. Journal of hazardous materials, 324, 634-644. https://doi.org/10.1016/j.jhazmat.2016.11.037

Price, K., and Farag, I. H. (2013). Resources conservation in microalgae biodiesel production. International Journal of Engineering and Technical Research, 1(8), 49-56. https://doi. org/10.1155/2013/930686

Saengsawang, B., Bhuyar, P., Manmai, N., Ponnusamy, V. K., Ramaraj, R., and Unpaprom, Y. (2020). The optimisation of oil extraction from macroalgae, Rhizoclonium sp. by chemical methods for efficient conversion into biodiesel. Fuel, 274, 117841. https://doi.org/10.1016/j.fuel.2020.117841

Samper, M. D., Bertomeu, D., Arrieta, M. P., Ferri, J. M., and López-Martínez, J. (2018). Interference of biodegradable plastics in the polypropylene recycling process. Materials, 11(10), 1886. https://doi.org/10.3390/ma11101886

Shahnawaz, M., Sangale, M. K., and Ade, A. B. (2019). Case Studies and Recent Update of Plastic Waste Degradation. In Bioremediation Technology for Plastic Waste (pp. 31-43). Springer, Singapore. https://doi.org/10.1007/978-981-13-7492-0_4
Singh, B., and Sharma, N. (2008). Mechanistic implications of plastic degradation. Polymer degradation and stability, 93(3), 561584. https://doi.org/10.1016/j.polymdegradstab.2007.11.008

Sivan, A. (2011). New perspectives in plastic biodegradation. Current opinion in biotechnology, 22(3), 422-426. https://doi. org/10.1016/j.copbio.2011.01.013

Sudhakar, K., and Premalatha, M. (2015). Characterisation of micro algal biomass through FTIR/TGA/CHN analysis: application to Scenedesmus sp. Energy Sources, Part A: Recovery, Utilisation, and Environmental Effects, 37(21), 2330-2337. https://doi.org/10.1080/15567036.2013.825661

Sue, T., Obolonkin, V., Griffiths, H., and Villas-Bôas, S. G. (2011). An exometabolomics approach to monitoring microbial contamination in microalgal fermentation processes by using metabolic footprint analysis. Applied and environmental microbiology, 77(21), 7605-7610. https://doi.org/10.1128/AEM.00469-11

Van Rensburg, M. L., S'phumelele, L. N., and Dube, T. (2020). The 'plastic waste era'; social perceptions towards single-use plastic consumption and impacts on the marine environment in Durban, South Africa. Applied Geography, 114, 102132. https:// doi.org/10.1016/j.apgeog.2019.102132

Verleye, G. A., Roeges, N. P., and De Moor, M. O. (2001). Easy identification of plastics and rubbers. iSmithers Rapra Publishing.

Vimal Kumar R, Kanna GR, Elumalai S (2017) Biodegradation of Polyethylene by Green Photosynthetic Microalgae. Journal of Bioremediation Biodegradation 08:1-8. https://doi. org/10.4172/2155-6199.1000381

Zhu, Y., Xu, S., and Yi, D. (2010). Photocatalytic degradation of methyl orange using polythiophene/titanium dioxide composites. Reactive and Functional Polymers, 70(5), 282-287. https:// doi.org/10.1016/j.reactfunctpolym.2010.01.007 